\title{
Being in a Position to Know is the Norm of Assertion Christopher Willard-Kyle
}

\author{
*Forthcoming in Pacific Philosophical Quarterly* \\ For citations, please use the final, published version: \\ https://onlinelibrary.wiley.com/doi/full/10.1111/papq.12305?af=R
}

\begin{abstract}
This paper defends a new norm of assertion: Assert that $p$ only if you are in a position to know that $p$. We test the norm by judging its performance in explaining three phenomena that appear jointly inexplicable at first: Moorean paradoxes, lottery propositions, and selfless assertions. The norm succeeds by tethering unassertability to unknowability while simultaneously untethering belief from assertion. The PtK-Norm foregrounds the public nature of assertion as a practice that can be other-regarding, allowing asserters to act in the best interests of their audience when psychological pressures would otherwise prevent them from communicating the knowable truth.
\end{abstract}

\section{Introduction}

What is the norm of assertion? Many have thought that, whatever it is, it is something epistemic. ${ }^{1}$ We assert, at least in part, to communicate information about the world: we add a proposition to the common ground (Stalnaker, 1978) or produce an attitude or reaction toward a proposition in an audience (Grice, 1969). Plausibly, in order for the speaker to be licensed in offering a proposition externally, they must stand in the right relation to the proposition internally. That is, the speaker must meet certain epistemic conditions with respect to the publicly asserted content. I argue that the relevant condition is being in a position to know:

\footnotetext{
${ }^{1}$ For a defense of the view that knowledge has a norm and that it is something epistemic, see Goldberg (2015a), especially chapters 1-3. This is not entirely uncontroversial, as this already rules out some proposals, notably Weiner's (2015) defense of the (semantic) truth norm. I take the epistemic character of the norm of assertion as a given, but see $\S 3.6$ for an argument that bears on Weiner's Gricean explanation of lottery propositions.
} 
PtK-Norm: One should assert that $p$ only if one is in a position to know that $p^{2}$,

The Position to Know Norm faces competition from two accounts that have shaped the contemporary debate: Timothy Williamson's knowledge norm and Jennifer Lackey's reasonable to believe norm.

K-Norm: One must: assert $p$ only if one knows $p$. (Williamson, 2000: 243) ${ }^{4}$

RTB-Norm: One should assert that $p$ only if it is reasonable for one to believe that $p$. (Lackey, 2007: 608) $)^{5}$

Williamson and Lackey offer different answers to two, distinguishable questions. Question (1): What epistemic property normatively guides our assertions? Williamson answers knowledge; Lackey reasonability. Question (2): Must the doxastic state of the asserter exemplify this property in order to assert properly? Williamson answers yes; Lackey no. Whereas Williamson claims that an agent ought to actually know the asserted proposition, Lackey claims that an agent may assert a proposition though she does not reasonably believe it, so long as it is reasonable for her to believe it.

I contend that the position to know norm preserves the best features of both proposals. It gets the correct verdict in Lackey's cases of selfless assertion. But it also gets the correct verdict in the lottery case and the Moorean paradoxes that are favorable to Williamson. The PtK-Norm gets the cases right by siding with Williamson on our first question and with Lackey on our second. First, knowledge is the property that normatively guides our assertions. But second, the doxastic state of the asserter

\footnotetext{
${ }^{2}$ Some philosophers argue that the norm of assertion is a constitutive norm-the sort of norm that makes assertion the thing that it is. Certainly this is Williamson's (2000) thesis. But this constitutive claim is separable from the claim that proper assertions ought to meet an epistemic requirement. In arguing for a norm of assertion, I do not take myself to be committed to the view that the norm is constitutive, only that it is binding. Of course, those who endorse the K-Norm will think that the PtK-Norm is trivially binding, since knowledge entails being in a position to know. So, properly understood, the thesis of this paper is really that the PtK-Norm is binding and that it is the most foundational epistemic requirement on proper assertion. I'm indebted to John Phillips for helping me clarify this point. ,

${ }^{3}$ Some theorists argue that there is a default norm of assertion that can, nevertheless, be modified across different contexts, as in 'conditions of epistemically diminished hope' (Goldberg, 2015a: 285) or when hedged (Benton and van Elswyk, 2020). My thesis should be understood as the claim that being in a position to know is the default norm of assertion.

${ }^{4}$ Cf. Unger (1975), DeRose (2002), Benton (2011, 2012, 2013, 2016), Sosa (2011). Turri's (2011) express knowledge norm and Goldberg's (2015a) nuanced thesis that knowledge is the default norm of assertion are important variants.

${ }^{5}$ Lackey's full formulation of the RTB-norm includes this second condition: 'if one asserted that $p$, one would assert that $p$ at least in part because it is reasonable for one to believe that $p^{\prime}$ (Lackey 2007: $608)$. But we'll return to this second condition in $§ 5$. Her official account is also augmented by a Not Misleading Norm that will be discussed in $\S 3$.
} 
need not exemplify this property (knowledge) for the agent to assert properly. It preserves Williamson's insight that knowledge is central to assertion while accommodating Lackey's insight that 'it is a mistake to require proper assertion to pass through the doxastic states of the asserter' (2007: 600). ${ }^{6}$

\section{A Provisional Account of the Position to Know}

The position to know is something like knowledge minus belief. Beyond this slogan, can we say more precisely what being in a position to know is? Here I offer a provisional account, intended to tell us enough to evaluate the PtK-Norm.

\subsection{General Features of a Position to Know}

Unlike knowledge and reasonability, the concept of being in a position to know is predominantly an epistemologist's term of art, finding scarce expression in ordinary parlance. We do sometimes say that someone 'could have known' or 'should have known,' but it's unclear how closely these expressions line up with the epistemologist's usage. A parent could and should have known how their child's day was because they could and should have asked-but not having asked, it's doubtful they are in an epistemic position to know. This does not mean that we have no independent grip on what it takes to be in a position to know or that the concept is philosophically unimportant: it does mean the concept requires explication.

Being in a position to know is a modal notion. One is in a position to know $p$ if one could know it under the right circumstances. One need not actually know to be in a position to know. So in order to determine whether someone is in a position to know $p$, we look across modal space to see if there is a world in which someone knows $p$ under the right circumstances. What circumstances are those? Those circumstances in which someone shares the agent's epistemic position.

This brings us to our second observation: When discussing what one is in a position to know, we are interested in the epistemic vantage point itself, not what use the agent has or is in fact psychologically capable of seeing from it. This is what it means to say that being in a position to know is knowledge minus belief-yet not just belief, but a broad range of facts about the agent's psychology. As a first pass (although important qualifications will be required), let us say that the position to know depsychologizes away from facts about the agent's particular mental states.

\footnotetext{
${ }^{6}$ In personal conversation, Lackey confirms that-at least on the right interpretation of epistemic position-her norm could be read as 'Assert that $p$ only if you are in a position to reasonably believe that $p$. ' This formulation makes especially salient the structural similarities between our accounts.
} 
Suppose, for instance, that a hypochondriac is psychologically incapable of believing that he does not have the flu. Multiple tests indicate that he has no symptoms, and his doctor testifies that he is in full health. In addition to having perfectly good evidence that he does not have the flu, it is true that he does not have the flu, and his epistemic situation is free from chancy or Gettierizing factors that might obstruct knowledge. The agent-because of his pathology-is unable to know that he does not have the flu. He is, nevertheless, in a position to know since the locus of the concept's evaluation is not the agent himself but the epistemic situation in which the agent finds himself. The epistemic position is what we are holding fixed in our evaluation. Someone in the agent's epistemic situation could know even if the agent himself could not: someone with a different psychological profile.

With these observations in place, we are now prepared to attempt a first pass at a definition of being in a position to know:

PtK: $S$ is in a position to know that $p$ iff $S$ could know that $p$ given their actual epistemic position.

We hold fixed the epistemic position of the agent, but what we don't hold fixed is just as important: we are free to vary other facts about the agent's beliefs and psychology. Of course, we're often (physically, psychologically) capable of changing our epistemic position, e.g., by asking someone a question. But one isn't in a position to know by being able to ask a question. Rather, by asking a question, one can move from a state of not being in an epistemic position to know the answer to being in an epistemic position to know it.

The proposed definition is useful as far as it goes. It captures the modal (could know) and depsychologizing (allowing psychological variation) structure of the concept. But it leaves some central questions unanswered: What is an epistemic position? And what epistemic position does an agent have to be in to be able to know that $p$ ?

\subsection{Constraints on Epistemic Position}

Whatever answer we give must satisfy some basic constraints on an adequate theory of epistemic position. At least, any such theory must respect the following four principles:

PtK to Truth: If $S$ is in a position to know that $p$ then $p$ is true. ${ }^{7}$

Knows to PtK: If $\mathrm{S}$ knows that $p$ then $\mathrm{S}$ is in a position to know that $p$.

\footnotetext{
${ }^{7} \mathrm{Cf}$. Williamson (2000: 95): 'Thus being in a position to know, like knowing and unlike being physically and psychologically capable of knowing, is factive.'
} 
PtK to No Further Inquiry: If $\mathrm{S}$ is in a position to know that $p$ then $\mathrm{S}$ does not require further inquiry to come to know that $p .{ }^{8}$

Anti-Collapse: For some $\mathrm{S}$ and for some $p$, it is possible that $\mathrm{S}$ is in a position to know that $p$ but does not know that $p$.

The first constraint says that being in a position to know is factive. ${ }^{9}$ The second says that knowing that $p$ is sufficient for being in a position to know that $p$. Knowledge, like most properties, can manifest without being disposed to manifest: a vase must be breakable in order to break, but it need not be fragile (disposed to break). This rules out certain dispositionalist accounts of the position to know, whereby to be in a position to know one must be (robustly enough) disposed to know under certain circumstances. ${ }^{10}$

What exactly counts as inquiry can be, for our purposes, left open. But our third condition encodes the idea that agents who are in a position to know already have at their disposal the means to know the target proposition. I'm not in a position to know what the capital of Estonia is merely in virtue of the fact that I could easily inquire by consulting an encyclopedia (or Google).

The final principle says, in effect, that there is no general inference from an agent's not knowing $p$ to the agent's not being in a position to know that $p$ : it's possible (and almost always true) that what an agent is in a position to know extends beyond what she actually knows.

There might be occasions in which one can infer from this particular agent's not knowing this particular proposition that the agent is not in a position to know it. A super-knower might know everything she is in a position to know. Propositions that are both self-evident (or near-enough) and attention-demanding (or what Chisholm (1982) called 'self-presenting') may always be known when their subjects are in a position to know them. For instance, 'I have a sharp headache' of 'I have an experience like this' might always be known by those in a position to know them. ${ }^{11}$ All our second principle says is that there is no general rule licensing this inference for

\footnotetext{
${ }^{8}$ Thanks to Ernie Sosa and Susanna Schellenberg for suggesting such a principle.

${ }^{9}$ Its factivity guarantees that the PtK-Norm satisfies what Ronald Jager calls the initial datum: 'to assert something is somehow to incorporate the claim that what is asserted is true' (Jager, 1970: 161).

${ }^{10}$ E.g. 'Being in a position to know a proposition is to be disposed to acquire the knowledge that the proposition is true, when one entertains it on the right evidential basis' (Stanley, 2008: 49).

${ }^{11}$ And then again, maybe not. Williamson's (2000) arguments for anti-luminosity are certainly relevant here.
} 
all agents and all propositions. What we are in a position to know far outstrips what we actually know.

A rough picture of the view we've sketched so far is that, when evaluating whether an agent is in a position to know that $p$, we hold fixed facts about the world beyond the agent's mind (the truth of the target proposition, whether the knower's context is free of Gettier traps) and vary facts about the agent's psychology (what beliefs they actually hold, any idiosyncratic psychological limitations they are subject to). We give the modal landscape a good shake and see if any worlds in which the agent knows that $p$ pop out.

This picture is missing one key ingredient-and it is here that we must qualify our characterization of the position to know as depsychologizing. Although epistemic position largely abstracts away from an agent's psychology, there must be something about the agent's mental life that we hold fixed: we must hold fixed whatever it is that fixes the agent's rational access to the world.

What does that mean? Answering that question puts us squarely in substantive epistemological territory. Plausible answers include an agent's evidence, an agent's evidence plus her priors or values, an agent's (epistemic) competencies, or an agent's way of looking at the world. Fortunately, the cases considered in the next section do not require that we take a stand on this substantive question. ${ }^{12}$ It's enough to note that a significant change of new, non-inferred evidence bearing on a proposition tends to put an agent in a new epistemic position toward it.

\footnotetext{
${ }^{12}$ This is, perhaps, a little quick. In particular, it's difficult to see how Williamson's E=K thesis, combined with an evidentialist interpretation of the position to know, fits this model. Suppose that the facts that make up an agent's epistemic position are exhausted by facts about the agent's evidence. For Williamson, your evidence is all and only what you know. Suppose that I am in a position to learn that $p$ at $\mathrm{t} 1$ and then come to believe $p$ and thereby know that $p$ at $\mathrm{t} 2$. For Williamson, at $\mathrm{t} 2 \mathrm{I}$ have special evidence for $p$ that I did not have at $\mathrm{t} 1$, namely the fact that $p$. At $\mathrm{t} 2$, my epistemic probability for $p$ conditional on my evidence is 1 though it may not have been 1 before.

The crucial thing for our purposes is that, on the $E=K$ thesis, coming to know something changes one's evidence (and so, plausibly, one's epistemic position) in an important way. On this picture, it is backward to try to evaluate whether an agent is in a position to know by assessing whether they could know holding fixed their prior epistemic position: coming to know that $p$ is always (or at least usually) to enter a new epistemic position with respect to $p$.

Here, I am forced to show my hand: I don't think the $\mathrm{E}=\mathrm{K}$ thesis is true. And part of the reason I think it isn't true is that I think evidence is a kind of support relation that is anti-reflexive (or at least, behaves anti-reflexively in typical cases). $P$ can't be evidence for itself, and so, even if only knowledge is evidence, it can't be that all knowledge is evidence bearing on any proposition: my knowledge that $p$ doesn't count as evidence for $p$, even if it counts as evidence for something else.

Still, we may be able to recover something like my account, even assuming a Williamsonian model. Perhaps we could introduce a notion of epistemically accessbile transitions from epistemic positions. If I am in a position to know that $p$, then there is an epistemically accessible transition from my current epistemic position to an epistemic position that includes my knowledge that $p$. I'm grateful to an anonymous reviewer for encouraging greater clarity on this point.
} 
A full theory of the position to know would say more about what exactly grounds our rational access to the world and exactly how and when an agent's psychological state can affect her position to know. Indeed, I take one of the main upshots of this paper to be that epistemologists ought to devote significantly more resources to understanding the position to know. Nevertheless, even without a full theory, we're capable of recognizing clear cases and of articulating some general conditions on the concept. 'Reasonability' and 'knowledge' are similarly contested terms, and so it's no dialectical disadvantage that there is no generally agreed upon theory. We've now said enough about the general structure of the position to know-that it depscyologizes and modalizes_to begin our assessment of the PtK-Norm of assertion.

\section{Three Cases}

How should we evaluate the norm of assertion? That depends on the theoretical work we want the norm of assertion to play. Why should we hope that there is a unified, simple, and epistemic norm of assertion in the first place?

There are two main reasons. First, assertions are a kind of affirmation, and as such it bears a close relationship to beliefs or judgments. ${ }^{13}$ Insofar as there are epistemic rules that govern our beliefs, we should expect that there are analogous bounds on assertion. I'll say more about the extent and limits of such similarities and why the PtK-Norm is the right sort of analogue in \$4. Second, there's a coordination problem for assertion that would be significantly resolved by a simple norm that operates, at least, as a default. There are several valuable epistemic goals that make plausible aims for assertion-truth, ${ }^{14}$ likely truth, reasonability, ${ }^{15}$ justification, ${ }^{16}$ supportive reasons, ${ }^{17}$ rational credibility, ${ }^{18}$ knowledge, ${ }^{19}$ and certainty ${ }^{20}$ among others. But if one person asserts with the aim of saying what is probable and another with the aim of saying what is certain, it will be hard to know how to update our opinions upon receiving testimony.

For this coordination problem, it matters very much what actual conventions are already in place, even if those conventions are robustly contingent. If everyone already drives on the right side of the road, then that very practice makes it sensible for there to be a norm to drive on the right side of the road, even if it would have

\footnotetext{
${ }^{13}$ Here I draw on Williamson (2000: 255-56) and Sosa (2011: 48).

${ }^{14}$ Weiner (2005)

${ }^{15}$ Lackey (2007)

${ }^{16}$ Kvanvig (2011)

17 McKinnon (2015)

${ }^{18}$ Douven (2006)

${ }^{19}$ Unger (1975), Williamson (2000), DeRose (2002), Benton (2011), Sosa (2011), a near-variant in

Turri (2011) and a sympathetic (though nuanced) account in Goldberg (2015a).

${ }^{20}$ Stanley (2008)
} 
been no worse for the practice to have developed in such a way that the sensible norm was to drive on the left. It is appropriate, therefore, for us to look at the actual linguistic practice of contemporary English speakers in order to determine what the norm is. By doing so, we freely confess that the norm of assertion we develop is only binding for contemporary English speakers: it's possible that other linguistic communities have solved the coordination problem for assertion in a different way.

I propose, therefore, that we test the PtK-Norm by seeing whether it gets the correct verdict in three cases: selfless assertions, Moorean paradoxes, and lotteries. These cases are not chosen at random, for these cases jointly pose a difficult puzzle. Moorean paradoxes and lotteries seem to show that nothing weaker than knowledge could be the norm of assertion. ${ }^{21}$ In the lottery case, for instance, one's epistemic position could be arbitrarily good short of knowledge and still fail to license the assertion that one's ticket lost. In contrast, selfless assertions seem to show that nothing as strong as knowledge could be the norm of assertion: any norm that entails even belief will be too strong. But this leaves no conceptual space for any norm of assertion to succeed: any norm will be too weak or too strong. Perhaps we need to give up our intuitions about one set of cases or the other.

Enter the PtK-Norm of assertion, which seamlessly delivers the correct verdict in all three cases. There is something weaker than knowledge that can play the role of the norm of assertion after all.

I won't say much to defend the intuitions that Lackey is right about selfless assertions and the knowledge camp are right about Moorean paradoxes and lotteries. I'll assume each side is correct about their favored cases (as I believe they are) and show why the PtK-Norm gets all three cases right. (As always, those who disagree with the starting intuitions can read the paper as defending a conditional claim.) But enough introduction-onto the cases.

\subsection{Selfless Assertions}

Lackey (2007) develops several cases of selfless assertion in which agents can properly assert $p$ despite not knowing $p$. In each case, the agent fails to know $p$ by failing to believe $p$. Here's one of her examples: ${ }^{22}$

\footnotetext{
${ }^{21}$ Sanford Goldberg summarizes part of Williamson's contribution this way: the 'KNA appears to be better positioned than any epistemically weaker standard to explain why lottery propositions...are not properly assertable even when the odds of one's winning are arbitrarily small' (Goldberg, 2015b). ${ }^{22}$ The distraught doctor case is not chosen from among Lackey's examples at random. I think the distraught doctor and racist juror case are more compelling than the creationist teacher case, in part (I contend) because it's unclear that the creationist teacher really is in a position to know (given their network of background beliefs) that evolution is true.
} 
DISTRAUGHT DOCTOR: Sebastian is [a] ...pediatrician [who] recognizes ...that all of the scientific evidence shows that there is absolutely no connection between vaccines and autism. However, shortly after his ...daughter received one of her vaccines, ...she was soon diagnosed with autism. ...[T] he grief and exhaustion brought on by his daughter's recent diagnosis cause him to abandon his previously deeply-held beliefs regarding vaccines. ...[W]hile performing a well-baby checkup..., the child's parents ask him about ...the rumors surrounding vaccines and autism. Recognizing both that the current doubt he has towards vaccines was probably brought about through [his] emotional trauma ....and that he has an obligation to his patients to present what is most likely to be true, Sebastian asserts, 'There is no connection between vaccines and autism' ... [although it's false that] Sebastian himself believes or knows this proposition. (Lackey, 2007: 598-99) ${ }^{23}$

Cases of selfless assertion are problematic for the knowledge norm of assertion, for they are cases in which agents properly assert what they do not know. Sebastian doesn't know that vaccines don't cause autism because he doesn't believe that vaccines don't cause autism. ${ }^{24}$ So how can he properly assert it?

The position to know norm, however, does not encounter the same difficulty. It isn't just rational for Sebastian to believe that vaccines cause autism: Sebastian is in a position to know it! The only thing he's missing is belief: if he were to believe it, he would thereby come to know it. The PTK-Norm thus accurately predicts that Sebastian can felicitously assert that vaccines do not cause autism.

There's a natural worry concerning Lackey's distraught doctor case: Given the high moral stakes, isn't it possible that moral intuitions are interfering with our more narrowly assertoric judgments? ${ }^{25}$

We can assuage this worry by developing a parallel case in which the moral stakes are not so high. Consider the following story:

\footnotetext{
${ }^{23}$ Requiring that testifiers know in order to transmit knowledge 'conflates reliable knowers with reliable testifiers' (Lackey, 1999: 481).

${ }^{24}$ It's worth flagging that there is a minority report in epistemology that knowledge does not entail belief (see, for instance, Carolyn Black (1971)). In this paper, l'll simply assume the orthodox position that knowledge entails belief, but the combination of views that includes the K-Norm of assertion and the thesis that knowledge does not entail belief is worthy of exploration.

${ }^{25}$ Thus Jonathan Kvanvig writes that though Lackey's selfless assertions 'are clearly appropriate, that intuition is fairly clearly an intuition about what is, all-things-considered, appropriate' (Kvanvig, 2011: 235 ) and do 'not survive scrutiny from an epistemic point of view' (Kvanvig, 2011: 235). But the locus of evaluation should not be purely epistemic but assertoric. Cases of selfless assertions just are ones in which the asserter fails as an epistemic agent by not having beliefs that are well-supported for them. The question is not whether selfless asserters perform well epistemically but whether they perform well assertorically despite their epistemic failings.
} 
Santa Claus: Jimmy has recently reached the age when he's too old to believe in Santa Claus. He has good evidence that Santa doesn't exist, and he is in a position to reasonably believe and even know that Santa doesn't exist. But for reasons having entirely to do with Jimmy's particular psychology, doubt persists-he can't fully believe (or thereby know) that there is no Santa. Perhaps he's afraid that if he doesn't believe in Santa, he won't get any presents. His brother, a year younger than Jimmy, asks him whether Santa exists. Jimmy replies: 'There is no Santa.'

The moral stakes are much lower in this story. In fact, to the extent that there are moral stakes, we are as likely as not to think that Jimmy was in the wrong-he oughtn't to have spoiled Santa for his brother! But even if Jimmy's assertion was morally wrong, it was assertorically felicitous (just as it can be felicitous but morally wrong to be rudely candid). Jimmy did nothing wrong in his duties as an asserter even if he failed his duties as a brother. And once again, Jimmy does not know the asserted proposition, though he is both in a position to know and reasonably believe it.

Our intuitions in cases of selfless assertion remain consistent even when there is no moral weight in favor of (and perhaps even some against) asserting a proposition. Lackey's cases illustrate how selfless assertions may be especially important in morally-loaded situations. But our judgments are not thereby captive to the purely moral elements of the cases.

\subsection{Roles to the Rescue?}

Prominent in Lackey's stories are the social roles (doctor, juror, teacher) of the selfless asserters. Thus Ernest Sosa suggests this strategy for the K-Norm to explain Lackey's cases:

I propose to accommodate [Lackey's cases] by means of a distinction between assertion in one's own person, as a human being who communicates with other human beings, and assertion as occupier of a role. ...One may still proceed with epistemic propriety if one is playing one's epistemic role properly. To play one's epistemic role in such contexts... one serves as a mouthpiece for a deeper institutional source of the information conveyed... (Sosa, 2011: 47). ${ }^{26}$

\footnotetext{
${ }^{26}$ Likewise, Kvanvig observes of a similar case that the asserter 'is being paid to fill a particular social role' (Kvanvig, 2011: 235).
} 
As applied to the case of the distraught doctor, this is to say that although Sebastian does not know that there is no connection between vaccines and autism in his own person, Sebastian does know it in his role as a doctor. The medical profession is the 'deeper institutional source of the information conveyed.'

Focusing on the role that an agent is in rather than the agent herself depsychologizes away from facts about the particular mental life of the agent. In this way, Sosa's response shares a core feature of the position to know hypothesis and respects Lackey's insight that proper assertions need not pass through the doxastic state of the asserter: proper assertion can go through a role-enabling social source instead. The central difference between Sosa's proposal and mine (along with Lackey's) is this: Sosa's account requires a deeper institutional source-or at any rate an established and recognizable social structure-within which the asserter occupies a role. The PtK-Norm (and the RTB-Norm) requires no such social source or role. Ostensibly in Sosa's favor is the fact that each of Lackey's cases does employ agents whose social role (e.g. doctor) is in focus. Nevertheless, we can develop compelling cases of selfless assertion that are not role or institution dependent.

Imagine, for instance, that Sebastian is not at work, but simply walking down the street when he overhears two parents discussing whether it is safe to vaccinate their child. Sebastian, ever eager to be helpful if not also a bit of a busybody, leans over and says, 'There is no connection between vaccines and autism,' before continuing on his way. Sebastian's assertion is still acceptable, even though (1) he does not know (because he does not believe) that there is no connection between vaccines and autism and (2) he at no point invokes-explicitly or implicitly-the social role of being a doctor. We might doubt the efficacy of Sebastian's assertion but not its felicity.

Or better yet, imagine that in the story above Sebastian is not a doctor at all, but simply someone who has happened to study the relevant evidence and recognizes its significance. Perhaps there aren't even doctors in Sebastian's community at all-he's just some guy who has looked at the evidence on the issue carefully. It is still felicitous for Sebastian to assert, 'There is no connection between vaccines and autism,' even though the role of doctor is entirely absent from the case.

It might be argued that just in virtue of asserting without knowledge, Sebastian creates a role for himself to speak from. He takes up the role of public informant about vaccinations and autism. In asserting something he does not know, he stops playing himself and plays the role of someone who knows what he is in a position to know. But if this is all that playing a role requires, then all assertions (or all public assertions, which are the dominant mode of assertions) involve taking on a certain 
social role (e.g. testifier, questioner, participant in an inquiry) so that it's inadequate to try to handle Lackey's cases of selfless assertion by bracketing them as a kind of special case. Assertion in a role-in this thin sense of role-is normal not exceptional, and the norm for assertion should reflect that. If one can always assert from the role of 'informant on proposition $p$,' one need not know that $p$ at all. It's sufficient to be in a position to know that $p$.

Merely appealing to roles cannot handle revised versions of Lackey's cases unless the concept of role is so thin as to make virtually any assertion an instance of assertion from a role: Either roles cannot explain all cases of felicitous, selfless assertion or else roles cannot distinguish cases of selfless assertion from normal assertions. Moreover, it's a virtue of the PtK-Norm that it can explain cases of selfless assertion without complicating the account by appealing to special roles. ${ }^{27}$

\subsection{Moorean Paradoxes}

Whereas the knowledge norm had trouble explaining the felicity of selfless assertions, the reasonable to believe norm has trouble explaining the infelicity of Moorean paradoxes. Moorean paradoxes are expressed when an agent makes the infelicitous assertion, ' $p$, but I don't know [or believe] that $p$.' Lackey explains why the RTB-Norm cannot get the right verdict on its own:

[I]t is reasonable for Sebastian in DISTRAUGHT DOCTOR to believe both that there is no connection between vaccines and autism and that he neither believes nor knows that this is the case. Accordingly, his asserting... 'There is no connection between vaccines and autism, but I don't know that this is the case' ...satisf[ies] the RTBNA (Lackey, 2007: 613).

But can't the exact same thing be said about the PtK-Norm? Consider the following argument:

Sebastian is in a position to know in DISTRAUGHT DOCTOR both that there is no connection between vaccines and autism and that he neither believes nor knows that this is the case. Accordingly, his asserting 'There is no connection between vaccines and autism, but I don't know that this is the case' satisfies the PTK-Norm (adapted from Lackey, 2007: 613).

\footnotetext{
${ }^{27}$ Likewise, McKinnon objects that Sosa's view 'seems to require all sorts of specialized norms of assertion, depending on one's institutional role' (McKinnon, 2015: 175). For a helpful, critical discussion of Sosa's defense of the K-Norm, see Christoph Kelp (2015).
} 
Isn't this a knock-down argument against the PtK-Norm? Or at least that the PtK-Norm, like Lackey's, needs to be supplemented? Consider, in contrast, how easily the K-Norm handles such cases.

If an agent knows that ' $p$, but I don't know that $p$,' then they know both that $p$ and that 'I don't know that $p$.' But they can only know that 'I don't know that $p$ ' if it's true that they don't know that $p$. So they both know and do not know that $p$-a contradiction! Since such propositions can't be known, the K-Norm elegantly explains why they also cannot be properly asserted. ${ }^{28}$

But note that the argument shows not just that Moorean propositions are unknown but that they are unknowable. This is good news for the PtK-Norm. For the fact that Moorean propositions are unknowable (for the speaker) rather than simply unknown explains why no one is in a position to know them. Consider the following argument:

(7) It is impossible for anyone to know a Moorean proposition. ${ }^{29}$

(8) If it is impossible for anyone to know a proposition, then no one is in a position to know it.

(9) Therefore, no one is in a position to know a Moorean proposition.

If this argument is sound, then the PtK-Norm can explain why Moorean propositions are not properly assertable just as easily as the K-Norm: One cannot properly assert Moorean propositions because one is never in a position to know them. The argument is valid. Premise (7) is just a consequence of Williamson's argument for the unknowability of Moorean propositions. The crucial premise, then, is (8). Is (8) true?

Premise (8) falls straight out of the definition of position to know that we considered earlier:

PtK: $S$ is in a position to know that $p$ iff $S$ could know that $p$ given their actual epistemic position.

If a proposition is impossible for a speaker to know, then the speaker could not know it from any epistemic position, much less from the epistemic position they are

\footnotetext{
${ }^{28}$ Cf. Williamson (2000: 253). DeRose notes that this is 'one of the most important' arguments for the K-Norm (2002: 180).

${ }^{29}$ Of course, here and in the following lines of the argument, I mean any Moorean proposition of which one is the subject. It's impossible for me to know ' $p$, but I don't know that $p$,' even if it is possible for you to know what is arguably the very same proposition (when addressed to me): ' $p$, but you don't know that $p$. ' But for me to be in a position to know a proposition, it must be possible for $m e$ to know it. For more on second-person variants of Moorean paradoxes, see Willard-Kyle (ms).
} 
actually in. Therefore, the PtK-norm can indeed explain why Moorean paradoxes are improper to assert.

But what of the argument we adapted from Lackey? Where did it go wrong? The mistake is the apparently innocuous move from being in a position to know each conjunct to being in a position to know the whole conjunction. Sebastian is in a position to know both 'that there is no connection between vaccines and autism,' and 'I [Sebastian] neither believe nor know that this is the case.' But this doesn't entail that Sebastian is in a position to know the conjunction 'that there is no connection between vaccines and autism and I [Sebastian] neither believe nor know that this is the case.' Indeed, as we just saw, it is impossible for Sebastian to be in a position to know a proposition of this form. Being in a position to know is not closed under conjunction. ${ }^{30}$

But isn't it strange that the proper assertability isn't closed under conjunction? According to the K-Norm, Moorean paradoxes are not properly assertable because one of the two conjuncts is not properly assertable. Either the agent doesn't really know that $p$ or doesn't really know that 'I don't know that $p$.' But according to the PtK-Norm, the agent is in a position to know both $p$ and 'I don't know that $p$ ' but not the conjunction of the two. The knowledge norm, unlike the position to know norm, seemingly maintains that a conjunction is properly assertable iff its conjuncts are each properly assertable.

\footnotetext{
${ }^{30}$ In his (2015a) Assertion, Goldberg considers (although he does not endorse) the PtK-Norm of assertion and even goes so far as to offer a friendly argument that the PtK-Norm can explain the infelicity of Moorean paradoxes. I believe, however, that his account is mistaken. His argument relies on the claim that 'being in a position to know... can be... defeated by being in a position to know that one does not know' (160). So then if one really were in a position to know that $\langle 1$ don't know that $p>$ one wouldn't be in a position to know that $p$. According to Goldberg, the agent who is in a position to know $<$ d don't know that $p>$ is neither in a position to know that $p$ nor the conjunction $<p$ but I don't know that $p>$ whereas on my view the agent can be in a position to know each conjunct of the Moorean proposition but not the conjunction.

It's easy to see the attraction of the principle that Goldberg proposes. If my total evidence is such that, if I reflected on it, I would not be doxastically justified (and so would not know) that $p$, plausibly I'm not in a position to know that $p$ now, even before l've reflected on the relevant evidence. So perhaps any time I'm in a position to know that I don't know that $p$, I'm not in a position to know $p$.

But the principle loses plausibility when we focus on cases in which the reason one knows that one doesn't know have nothing to do with the epistemic quality of the belief in question. If I am in a position to know-or even know outright-that I do not know that $p$ but only because I know I can't psychologically get myself to believe $p$, this doesn't exclude me from being in a position to know that $p$. Lackey's case of Sebastian the doctor is useful here. Sebastian might be well aware that he can't get himself to outright believe that <there is no connection between vaccines and autism>. So he knows (and a fortiori is in a position to know) that he does not know <there is no connection between vaccines and autism $>$, since knowledge entails belief. But this in no way prevents Sebastian from being in a position to know that <there is no connection between vaccines and autism>. What's so frustrating about Sebastian's psychological position is (among other things) that he can't get himself to believe what he is in a position to know.
} 
Indeed, it is intuitive that the proper assertability of conjunctions supervenes on the proper assertability of their conjuncts. The truth of conjunctions supervenes on the truth of their conjuncts, and knowledge—as a truth-seeking state-often follows suit.

Intuitive, but false. Consider the preface paradox. An author believes-and we might add, asserts-each individual proposition in a book she publishes. But in the preface, she humbly adds, 'Despite the tremendous help I have received from my colleagues in writing this book, I have surely made some mistakes here and there. All errors are, of course, my own.' She believes, on the basis of good meta-inductive evidence, that one of the propositions she believes (and asserts) in the book is false. For each proposition in the book, she believes it. But she does not believe the conjunction of all her beliefs.

Little changes if we add that-miraculously—she in fact knows (and, a fortiori, is in a position to know) every individual proposition in the book. It is still not rational for her to believe the conjunction of every proposition: the meta-inductive evidence that she's made a mistake somewhere is too strong. And if it isn't rational for her to believe the entire conjunction, she neither knows nor is in a position to know the conjunction. So even on the knowledge norm, proper assertability is not closed under conjunction.

Thus, the PtK-Norm and the preface paradox share a common consequence. In both cases, to determine whether an agent is in a position to know a conjunction of propositions, we must look at more than just whether the agent knows each proposition individually but at how the agent's epistemic access to each proposition reacts when combined with others. In the preface paradox, the chance of error of the whole compounds when each conjunct is asserted not independently but as a part of a conjunction. In the case of the Moorean paradox, none of the accessible worlds that explain the agent's being in a position to know $p$ overlap with the worlds that explain the agent's being in a position to know that 'I don't know that $p$.' Although there are worlds in which an agent in the speaker's epistemic position knows that $p$ and worlds in which an agent in the speaker's epistemic position knows that 'I don't know that $p$,' there are no worlds in which an agent knows both propositions. In both paradoxes, confusion is avoided by refusing to reduce the assertability of a conjunction down to the assertability of its conjuncts.

Here's a different worry: Sometimes it's not clear when someone has asserted a conjunction instead of merely the separate conjuncts. The mere presence of a conjunction such as 'and' or 'but' can't be the only factor. It would be just as bad for Sebastian to tell his patient, 'There is no connection between vaccines and autism: I don't know that this is the case,' although, when spoken instead of written, nothing overtly signifies that the propositions are conjoined. So in borderline cases, how are 
we to tell whether Sebastian has asserted a conjunction or merely two discrete propositions?

Plausibly, there are clear cases on either side. Suppose Sebastian says to his patient, 'There is no connection between vaccines and autism,' and adds in a hushed tone, 'but I don't know that this is the case.' Merely hushing the second clause is not enough to absolve him of having asserted the whole conjunction rather than two simple propositions. On the other hand, if Sebastian says to his patient, 'There is no connection between vaccines and autism,' and then rushes across the hall to his therapist's office to lament, 'I don't even know that what I said is true!' Sebastian has not asserted the whole conjunction but only two simple propositions in close temporal proximity. But there will be cases in which it's not obvious whether Sebastian has asserted the whole conjunction or just each would-be conjunct. If both his patient and his therapist are in the room and Sebastian says, 'There is no connection between vaccines and autism,' before sharply turning to his therapist and adding, 'I don't know that what I just said is true,' has he asserted the whole conjunction or merely two unjoined propositions in near temporal succession? It's not clear, and so it's not clear what the position to know hypothesis predicts is properly assertable. It's also unclear whether or not this assertion (or assertions) is (or are) felicitous.

I answer: It is no knock on a theory that it predicts confusion where confusion is. We feel genuinely confused about whether Sebastian has asserted properly when it's unclear whether his assertion is a conjunction or two discrete statements in close proximity. It's evidence for the PtK-Norm and not against it that the cases in which our intuitions are muddled covary with cases in which it's unclear what the PtK-Norm predicts. This is precisely where we should expect to be confused if the PtK-Norm is true: it's further evidence that we implicitly appeal to the PtK-Norm to determine whether an assertion is felicitous.

\subsection{Lotteries}

In addition to Moorean paradoxes, the RTB-Norm struggles to explain assertions about lotteries. Williamson writes:

Suppose that you have bought a ticket in a ...lottery. ...[Y]our ticket did not win, but I have no inside information to that effect. On the merely probabilistic grounds that your ticket was only one of very many, I assert to you flat-out 'Your ticket did not win'... [M]y grounds are quite inadequate for that outright unqualified assertion. ...I was representing 
myself to you as having a kind of authority to make the flat-out assertion which in reality I lacked (Williamson, 2000: 246). ${ }^{31}$

The knowledge norm explains why it's impermissible to assert 'Your ticket lost' even when the odds are arbitrarily high. Exactly why we cannot know lottery propositions without special evidence is a matter of debate, but plausibly it's something like this: Knowledge requires the elimination of (salient) chance. And it's very salient in lottery cases that there is a chance-however small-that your ticket will win. ${ }^{32}$

Lottery cases show that one's evidence could make a proposition as likely as one likes (shy of 1) and still fail to warrant assertion. This puts pressure on the reasonable to believe norm. Lackey concurs:

[T] he very good probabilistic grounds for lottery propositions presumably render it reasonable to believe in their truth. Hence, so long as a speaker asserts a lottery proposition ....because of this reasonableness, these assertions are taken to satisfy the RTBNA (Lackey, 2007: 613).

But unlike the RTB-Norm, the PtK-Norm gets the intuitively correct verdict. It isn't just that agents don't know lottery propositions without special evidence: they can't know them. Lotteries aren't the right places to go looking for knowledge: the terrain is too full of luck and salient chances for knowledge to survive without special evidence.

(10) It is impossible for anyone to know that <this ticket lost the lottery> without special evidence (e.g. inside information on the result of the draw).

(11) If it is impossible for anyone to know that <this ticket lost the lottery> without special evidence, then no one without special evidence is in a position to know it.

(12) Therefore, no one without special evidence is in a position to know that $<$ this ticket lost the lottery>.

This argument closely resembles our argument that no one is in a position to know Moorean paradoxes. A notable difference is that lottery propositions are not absolutely impossible to know but only impossible to know without special evidence. Consider again PtK:

\footnotetext{
${ }^{31}$ Williamson later clarifies: 'There is a special jocular tone in which it is quite acceptable to say '[Come off it-] Your ticket didn't win', but the tone signals that the speaker intends not to make a flat-out assertion. In the imagined example, I do not use that tone' (Williamson, 2000: 246).

${ }^{32}$ As Lackey reminds us, 'it is not universally accepted that subjects do in fact lack knowledge in lottery propositions' (Lackey, 2007: 617). Nevertheless, for the purposes of this paper, I take as given the orthodox position that we do not know lottery propositions.
} 
PtK: $\mathrm{S}$ is in a position to know that $p$ iff $\mathrm{S}$ could know that $p$ given their actual epistemic position.

Premise (11) is true if obtaining (new) special evidence changes one's epistemic position. Clearly, obtaining special evidence quite dramatically changes one's epistemic position. Therefore, premise (11) is true. If one can't know lottery propositions in normal evidential circumstances, then one isn't in a position to know either. Thus the PtK-Norm, unlike the RTB-Norm, correctly predicts that lottery propositions are not properly assertable in ordinary evidential contexts.

\subsection{Why the Not Misleading Norm is not Enough}

Lackey is well aware of the challenges Lottery cases and Moorean paradoxes pose for the RTB Norm. To resolve this tension, Lackey augments the RTB norm with the Not Misleading Norm of Assertion. The final version of this principle reads thus:

NMNA**: $\mathrm{S}$ should assert that $p$ in context $\mathrm{C}$ only if it is not reasonable for $\mathrm{S}$ to believe that the assertion that $p$ will be misleading in $C$ relative to the purposes of the exchange in question (Lackey, 2007: 615).

One source of discomfort for NMNA** is the ease with which we as reasoners can be misled by making irrational yet predictably human inferences. I find that when I focus on how easy it is for an assertion to be misleading, and how onerous such misdirection can be to contain, I lose the intuition that a speaker can never assert that $p$ if they reasonably believe that it will be relevantly misleading in some way. Because humans are subject to widespread and deeply ingrained biases, it's often very hard not to be misleading in some way or another. And especially if the reason it's hard not to be misleading is that the auditor is being unfair or irrational, it seems overly-demanding to require that the speaker eliminate all reasonably anticipated sources of relevant misdirection before asserting. Suppose, for instance, that when her education is being discussed in a certain society, men are disposed to believe that the speaker has gone to secretarial school even if she in fact studied philosophy. It seems overly cumbersome for the norm of assertion to demand that she always add 'but I didn't attend secretarial school!' when mentioning her education, even if her education is contextually relevant and the speaker knows full well that her audience is drawing a false conclusion. Her assertion is, through no fault of her own, misleading in a contextually relevant way, but it's not the assertoric responsibility ${ }^{33}$ of the speaker to correct this particular kind of misdirection. ${ }^{34}$

\footnotetext{
${ }^{33}$ Of course, there may be cases in which we have moral reasons to contain misdirection even when it isn't our narrowly assertoric duty to do so.

${ }^{34}$ Another way to interpret this case is as one in which the speaker is not misleading (the speaker is just telling the truth!) but the audience is being misled by their own preconceptions (or by the systemic
} 
But there is an even deeper reason to be dissatisfied with the attempt to save the RTB-Norm by tacking on NMNA**. Lackey owes us an answer to this question: Why is it that Moorean paradoxes and lottery propositions are misleading? We should want, in our theory of assertion, not just a norm that prohibits being misleading but an explanation whence the misdirection comes.

If knowledge is the guiding normative property for assertion (as both the K-norm and PtK-norm maintain), there is a natural answer to the question of why lottery propositions and Moorean paradoxes are misleading: assertions present their speakers as (at least) in a position to know the asserted proposition, and lottery propositions (in normal evidential circumstances) and Moorean paradoxes are unknowable. But if we don't normally assume that people are in a position to know what they assert, why are we confused when confronted with lottery propositions and Moorean paradoxes?

At this point, proponents of the RTB-norm might return to the Gricean injunction to make one's assertions as informative as one can: Don't say things everyone already believes (cf. Weiner, 2005). And everyone already reasonably believes (on Lackey's account) that you've lost the lottery. So when someone says, 'you lost the lottery,' for instance, they violate the mandate of informativeness. We naturally resolve this violation by charitably assuming that the speaker be in an even better epistemic situation than the rest of us. That would explain why they flouted the conversational maxim of informativeness. But this response falls short. For it's still improper to flat-out assert 'you lost the lottery,' even when explaining lotteries to a lottery-novice who doesn't have any idea what will happen to their ticket. ${ }^{35}$

\subsection{Knowledge-Oriented Varieties of Reasonability}

Perhaps Lackey was too quick to concede that the relevant kind of reasonability did not secure the right judgment all by itself. Douven (2006, 2009) and Kvanvig (2009) propose broadly reasonability-based norms of assertion (rational credibility and

\footnotetext{
injustice of the society). The speaker isn't misleading her audience, rather she is letting her audience be misled by their own biases. The misdirection is occasioned but not caused by her speech. But introducing this distinction raises a challenging question for the $N_{M A}{ }^{* *}$. For suppose I say that you have lost the lottery (which it turns out, unsurprisingly, that you have). I am telling you something true. Why is it that I count as misleading you in this case rather than simply letting you be misled by your preconception that I would only tell you that you had lost if I had insider information? It is, at least, not obvious how to draw the line between misdirecting and allowing to be misled in such a way that the lottery case and Moorean paradoxes come out on one side and the mistaken-for-a-secretary case comes out on the other. Thanks to an anonymous reviewer for conversation on this point.

${ }^{35}$ Note, too, that the assertion is not helped by adding more information: 'Your ticket lost because there are so many tickets that it is exceedingly unlikely that you won,' is just as bad if not worse than the less informative 'your ticket lost.'
} 
justification respectively) that, they argue, secure the intuitive verdict in Moorean paradoxes and lottery propositions without any additional norms.

Thus Kvanvig says that assertion requires justification of 'the kind that puts one in a position to know' (Kvanvig, 2009: 149). ${ }^{36}$ And Douven builds this principle into his account of rational belief: $\operatorname{RB}_{i}(\varphi) \Rightarrow \mathrm{Cr}_{i}\left(\mathrm{~K}_{i}(\varphi)\right) \geqslant \mathrm{Cr}_{i}\left(\neg \mathrm{K}_{i}(\varphi)\right)(2009$ : 371). Roughly, if an agent rationally believes a proposition, then their credence that they know it is higher than their credence that they don't. On this account, one can't rationally believe that ' $p$, but I don't know that $p$ ' because that would require believing that it's both more and less probable than not that I know that $p$.

But Douven's principle is contentious. Plausibly, it is possible to rationally believe (or even know) a proposition while simultaneously having a higher credence that one does not know that proposition than that one knows it.

This is most compelling when an agent has misleading evidence that they do not know. Imagine, for instance, someone living in a community of Ungerian (1975) skeptics. Such skeptics maintain their ordinary beliefs, but because they think the demands of knowledge are very high, they think that (almost) none of their beliefs constitute knowledge. In such a community, agents might have very good testimonial evidence that they do not know what they believe-after all, everyone in that community says that Ungerian skepticism is true. But if they continued to form beliefs in the normal way (despite a commitment to an epistemological theory that these believings, however well-supported, never constituted knowledge) by perception, valid reasoning, etc., l'd be inclined to say that their ordinary, first-order beliefs were still rationally believed (and known!) even if their credence that those beliefs were knowledgeable was near $0 .{ }^{37}$

But there's a deeper dissatisfaction that affects both Douven's and Kvanvig's accounts. Why is it that justification requires being of the sort that puts one in a position to know? Or why does rational belief require thinking it more likely than not that one knows what one believes? Presumably because beliefs are aimed, in some sense, at knowledge. Otherwise, why care that one's beliefs fall short of knowledge rather than, e.g., truth or probable truth? For the varieties of reasonability that Douven and Kvanvig care about (rational credibility and justification), one has only really been reasonable if one has done well enough with respect to knowledge.

\footnotetext{
${ }^{36}$ For Kvanvig, the justification need not actually put the speaker in a position to know since the content of the assertion could be false or Gettiered. But it can't be a defect in the speaker's justification that they are not in a position to know.

${ }^{37}$ Admittedly, such a community would plausibly have a different norm of assertion than the one the community of contemporary, English speakers have developed. The restricted point here is that Douven's epistemic principle is contentious. Thanks to an anonymous reviewer for encouraging further clarity on this point.
} 
This gives knowledge uncomfortable pride of place in apparent competitors to the thesis that knowledge is the epistemic property central to assertion. There's a principled reason Lackey appeals to an accuracy-based account of reasonability as she engages Williamson's arguments. For suppose that in order to be reasonable (or justified or rational) one aims not just to be accurate but to know, and that in order to properly assert one aims to be reasonable. Then in aiming to properly assert one would also aim to know, since it is by aiming at knowledge that one achieves the aim or reasonability. But once it's admitted that we aim to know in order to properly assert, it's hard to resist the pull of the knowledge norm. If knowledge is the ultimate aim of reasonability, then why should assertion aim at a merely derivative goal? Better to say that knowledge is the normatively guiding property for both belief and assertion. ${ }^{38}$

\subsection{Putting the Audience in a Position to Know}

Now that we've examined the importance of Moorean paradoxes, we're able to consider one more attempt to explain selfless assertions. Like Lackey, I have explained selfless assertions by dropping a belief requirement on assertion. But we both maintain that it is the epistemic position of the speaker that enables proper assertion. A more radical solution would be to deny that the speaker must be in any particular epistemic position to properly assert. García-Carpintero and Pelling have each proposed norms that focus not on the originating epistemic position of the speaker but on the resulting epistemic position of the audience:

TKR: One must ((assert $p$ ) only if one's audience comes thereby to be in a position to know p) (García-Carpintero, 2004: 134).

PKA: One's assertion that $p$ is proper only if it is fit to give a hearer knowledge that $p$ (Pelling, 2013: 297). ${ }^{39}$

As I argue in more detail elsewhere (ms), such assertions cannot explain the felicity of certain second-person variants of Moorean paradoxes. For instance, it would be felicitous for Jean Valjean to tell Inspector Javert, 'You'll never believe that I've changed even though I have!' This is something the speaker, Jean Valjean, is in a position to know. But Javert, the intended audience, couldn't possibly know that Javert has changed and that he'll never believe it: that would commit Javert (but not

\footnotetext{
${ }^{38}$ See $\$ 4$ for more on the relationship between the norms of belief and assertion.

${ }^{39}$ In later work, Pelling modifies this view, claiming that that an interpersonal norm such as knowledge provision is better understood as a norm for the speech act of telling than the speech act of asserting, a distinction he makes in Pelling (2014). (He notes his change of view in 2013: 348, fn. 9.)
} 
Valjean) to a Moorean paradox! $!^{40}$

If it's impossible for one's audience to know a proposition, it is neither fit nor possible to put the audience in a position to know that proposition. The PtK-Norm rightly maintains that it is the epistemic position of the speaker rather than the audience that licenses proper assertion, while still allowing speakers the flexibility to make selfless assertions in the best interests of their audience..$^{41}$

\section{Assertion and Belief}

There's another important argument against the PtK-Norm-especially favored by the knowledge camp-from the apparent similarities between assertion and belief. Williamson and Sosa both argue that the knowledge norm of assertion illuminates a deep parallel between assertion and belief. Williamson writes:

[O]ccurently believing $p$ stands to asserting $p$ as the inner stands to the outer. If so, the knowledge rule for assertion corresponds to the norm that one should believe $p$ only if one knows $p$ (Williamson, 2000: 255-56).

Likewise, Sosa says:

If knowledge is the norm of assertion, it is plausibly also the norm of affirmation, whether the affirming be private or public (Sosa, 2011: 48). ${ }^{42}$

It is a negotiable feature of a theory of assertion that the norms of belief and assertion thus align. But suppose that Williamson and Sosa are right: the parallels between belief and assertion run deep. Insofar as knowledge is the norm of belief, austerity in our theorizing favors the knowledge norm of assertion.

The problem can be cast in a broader way. The norms governing belief do pass through the doxastic state of the asserter-the doxastic state of the asserter is what we are evaluating when we evaluate belief. We need an answer to the question of how best to evaluate an agent's beliefs. Perhaps an agent should believe $p$ only if her belief constitutes knowledge; perhaps an agent should believe $p$ only if her belief is rational or supported by good reasons. At any rate, once we've decided on an answer to that question, why not simply cross-apply that norm to assertion?

\footnotetext{
${ }^{40}$ Note that since the claim includes that Javert will never believe that Valjean has changed, Javert cannot come to know this proposition in the future as well as at the time of utterance.

${ }^{41}$ For more on what we can learn from second-person variants of Moorean Paradoxes, see Whitcomb (2013) and Willard-Kyle (ms).

${ }^{42}$ As Goldberg notes, these insights from Williamson and Sosa are anticipated by Dummett:

'Judgment . . . is the interiorization of the external act of assertion' (Dummett, 1973: 362; cited in Goldberg, 2015b: 376).
} 
The first answer to this question is the principal retort to every objection from parsimony: the PtK-Norm gets more cases right, and this is what justifies a distinct norm for assertion. This is the conclusion for which the paper has argued so far. But I think we can do better than this. There are reasons to expect the norms of assertion and belief to separate and to separate in precisely the way the PtK-norm predicts.

Williamson and Sosa hold that belief and assertion share an important similarity (the same norm), but they also hold that there's an important difference: the difference between inner and outer, or private and public. It is this very difference that explains why the norms, too, diverge. There's a good reason that the norms for belief may require something (knowledge or rational belief) that passes through the doxastic state of the asserter-the inner, doxastic state itself is what is under evaluation. In contrast, the norm of assertion is not an evaluation of a doxastic state, but of an outer utterance. ${ }^{43}$

Closely related to this distinction between inner and outer is the distinction between other-affecting and non-other-affecting aims. Indeed, it is the other-affecting aim of assertions that requires that assertions be outer acts in a way that beliefs are not. Typically, when a speaker decides to assert, she thereby decides to try to bring about a certain attitude in her audience. In contrast, when an agent decides to believe, she thereby decides to bring about a certain attitude in herself. There may be exceptions, as when a cleverly framed defendant asserts their innocence against all hope of persuasion or of shifting the common ground. But even in these cases, the other-affecting quality of assertion is invoked to explain why such assertions feel helpless. To assert when no one will believe what you assert is to have one's act frustrated: to believe when no one will share your belief may be lonely, but it is not to have one's act frustrated in the same way.

Once we have it fixedly in mind that assertion is an outer and typically other-affecting act, it becomes puzzling why assertion should require the asserter to be in any particular doxastic state. The doxastic state of the audience is at issue, not of the speaker. This is why it makes sense to focus, as Lackey does, on assertions that are selfless. What Lackey identifies as the selfless quality of assertion is the consequence of its other-regarding character. Assertions can be selfless precisely because assertions are other-regarding.

\footnotetext{
${ }^{43} \mathrm{Cf}$. Goldberg: 'Assertion is a public act, whereas belief is neither an act nor a public matter, and there are reasons to think that both of these differences bear on the respective standards of each' (2015a: 167).
} 
Consider: the hearer is at no disadvantage if she receives testimony from those who are merely in a position to know rather than those who actually know. The quality of information received is just as high. Propositions one is in a position to know have the quality Goldberg calls 'aptness for communicating knowledge' (Goldberg, 2015a: 6). And since the set of things a speaker knows is a subset of the things she is in a position to know, audiences do better with respect to the quantity of propositions from asserters who assert what they are in a position to know rather than merely what they know. Since the quantity of asserted propositions is larger and the quality of asserted propositions no worse, the PtK-Norm is an intuitively better policy for transmitting information.

It seems, therefore, that we do have good reason for having distinct norms for assertion and belief: assertion is immediately other-regarding in a way that belief is not. Indeed, we had to look little further than Williamson's and Sosa's own characterizations of the chief difference between belief and assertion-that of private and public_-to find such a reason.

\section{Are We in a Position to Know Too Much?}

Someone might object: What we are in a position to know far outstrips what we know. This makes it too easy for someone to accidentally follow the norm. Suppose that you are asked where Tom is and that you don't know the answer-you don't have any belief about where Tom is right now. But instead of confessing your ignorance, you pick a place at random: 'Tom's at the bar.' You brush off your inquisitor and give Tom's location not a second thought. As it turns out, Tom is at the bar. More than that, you remember that he told you yesterday that he would be at the bar at seven, and you know perfectly well that it's seven now. If you'd bothered to think about the question at all, if you'd bothered to put your evidence of Tom's testimony together with your evidence about the current time, you would have known that Tom is at the bar. So you're in a position to know that Tom is at the bar. But the assertion seems awful! The PtK-Norm, it seems, cannot explain this.

This problem of random assertions that happen to conform to the norm is not, however, unique to the PtK-Norm. It's a general feature of all norms, as Kant taught us, that norms give rise to at least two species of criticisms: (1) not acting in accordance with the norm, and (2) not acting out of respect for the norm. In the story above, Tom is criticizable for not acting out of respect for the norm even though he (by accident) acts in accordance with the norm.

Note that the primary competitors we have considered also face the same sort of objection. If you're in a position to know that Tom is at the bar, it's also reasonable for you to believe that Tom is at the bar, so the case above is equally a problem for 
the RtB-Norm. A slightly modified version of the case shows that it is also a problem for the K-Norm. Suppose that the speaker knew (perhaps non-occurrently) that Tom was at the bar but said so for reasons entirely unconnected to that knowledge. Irritated by the question about Tom's whereabouts, the speaker picks the location in town furthest from their current location. It is only afterward-and with some regret-that the speaker later realizes that his answer helped rather than hindered the inquiry. ${ }^{44}$

Lackey proposes a strategy for handling such cases. She builds a second condition into her norm: 'if one asserted that $p$, one would assert that $p$ at least in part because it is reasonable for one to believe that $p^{\prime}$ (Lackey 2007: 608). ${ }^{45}$ Analogous clauses could be built for the PtK- and K-Norms, e.g., we could add the second condition that 'if one asserted that $p$, one would assert that $p$ at least in part because one is in a position to know that $p$.' Adding such a clause seems to solve the problem. Asserting a proposition at random is wrong since it is not asserted because of its epistemic standing, even if the proper epistemic standing is (as it so happens) possessed by the asserter.

Despite the obvious appeal of Lackey's suggestion, I am hesitant to adopt it. Do norms in general tend to have the form, 'one ought to do the right thing' or 'one ought to do the right thing (at least in part) because it is the right thing?' Surely it is better to do the right thing for the right reason, but is such a condition baked into the norm itself? At least not obviously. For one thing, it makes sense to talk of someone doing the right thing for the wrong reason-and even doing the right thing only for wrong reasons, so that their right action is in no way caused or explained by its being the right thing to do. In Kantian terms, one can act in accordance with duty without acting from duty. But building the right causes, reasons, or expression ${ }^{46}$ into the norm itself threatens to obfuscate this distinction. ${ }^{47}$

Moreover, once we have this Kantian distinction in mind, it's no longer a mystery why we should say that asserting things at random is bad even if it should happen to satisfy the norm of assertion (whatever that norm may be). Agents can be criticized not only for violating the norm but for being insensitive to the guidance of the norm in asserting. It's a general feature of norms that there are these two levels of criticism, and all norms of assertion will need to invoke this distinction (or one like it) to handle the general problem of random assertions.

\footnotetext{
${ }^{44}$ Cf. Turri (2011: 41) for a similar case.

${ }^{45}$ McKinnon follows Lackey's lead and builds a similar condition into her supportive reasons norm (McKinnon: 2015: 52).

${ }^{46}$ As in Turri (2011)

${ }^{47}$ I'm grateful to Tom Kelly for conversation on this point.
} 


\section{Conclusion}

We began by sketching an account of an often employed but rarely fully characterized concept: the position to know. The position to know depsychologizes away from the agent so that it is possible for an agent to be in a position to know what they do not believe. But the position to know shares many important features with knowledge: importantly, being in a position to know that $p$ entails that $p$ is both true and knowable.

This unique combination suggests a promising norm of assertion: Agents should assert that $p$ only if they are in a position to know it. This norm gets the right verdict in selfless assertions, lotteries, and Moorean paradoxes by balancing Williamson's (etc.) insight that knowledge is central to assertion with Lackey's insight that assertion is other-regarding. The PtK-Norm thus foregrounds the public nature of assertion that allows asserters the flexibility to act in the best interests of their audience when internal psychological pressures would otherwise prevent them from communicating the knowable truth. ${ }^{48}$

Rutgers University, New Brunswick

Department of Philosophy

\section{References}

Benton, Matthew A. (2011). 'Two More for the Knowledge Account of Assertion,' Analysis 71(4):684-687.

Benton, Matthew A. (2012). 'Assertion, Knowledge and Predictions,' Analysis 72 (1):102-105.

Benton, Matthew A. (2013). 'Dubious Objections from Iterted Conjunctions,' Philosophical Studies 162:355-358.

Benton, Matthew A. (2016). 'Gricean Quality,' Noûs 50 (4):689-703.

Benton, Matthew A. \& Van Elswyk, Peter (2020). 'Hedged Assertions,' in Sanford Goldberg (ed.), The Oxford Handbook of Assertion, Oxford: Oxford University Press:245-263.

Black, Carolyn (1971). 'Knowledge without Belief,' Analysis 31 (5):152-158.

\footnotetext{
${ }^{48}$ I owe thanks to a large community of people for criticism, helpful suggestions for improvement, and insistence on clarity. In particular, I'm grateful to Matt Benton, D Black, Laura Callahan, Sam Carter, Christopher Copan, Charles Côté-Bouchard, Andy Egan, Megan Feeney, Danny Forman, Chris Frugé, Adam Gibbons, Sandy Goldberg, Chris Hauser, Caley Howland, Matt McGrath, Tom Kelly, Savannah Kinkaid, Nico Kirk-Giannini, Jennifer Lackey, Ting-An Lin, Dee Payton, John Phillips, Pamela Robinson, Ezra Rubenstein, Susanna Schellenberg, Ernie Sosa, and the anonymous reviewers for helpful feedback on versions of this paper. Special thanks to Carolina Flores and Elisabeth Camp who each read the paper several times and always told me many things that they were in a position to know would improve the paper.
} 
Chisholm, Roderick M. (1982). The Foundations of Knowing, Minneapolis: University of Minnesota Press.

Dahlback, Morten (forthcoming). 'Infinitely Permissive' Erkenntnis.

DeRose, Keith (2002). 'Assertion, Knowledge, and Context.' The Philosophical Review 111:167-203.

Douven, Igor (2006). 'Assertion, Knowledge, and Rational Credibility,' The Philosophical Review 115 (4):449-485.

Douven, Igor (2009). 'Assertion, Moore, and Bayes,' Philosophical Studies 144:661-375.

Dummett, Michael (1973). Frege's Philosophy of Language, New York: Harper and Row.

Grice, H.P. (1969). 'Utterer's Meaning and Intention,' Philosophical Review 78 (2):147-177.

Goldberg, Sanford C. (2015a). Assertion: On the Philosophical Significance of Assertoric Speech, Oxford: Oxford University Press.

Goldberg, Sanford C. (2015b). 'Recent Work on Assertion,' American Philosophical Quarterly 52 (4):365-380.

Jager, Ronald (1970). 'Truth and Assertion,' Mind 79 (314):161-169.

Kelp, Christoph (2015). 'Sosa on Knowledge, Assertion and Value,' Erkenntnis 80:229-237.

Kvanvig, Jonathan (2009). 'Assertion, Knowledge, and Lotteries,' In Duncan Pritchard \& Patrick Greenough (eds.), Williamson on Knowledge. Oxford: Oxford University Press, pp. 140-160.

Kvanvig, Jonathan (2011). 'Norms of Assertion,' in Jessica Brown and Herman Cappelen (eds.) Assertion: New Philosophical Essays, Oxford: Oxford University Press, pp. 233-250.

Lackey, Jennifer (1999). 'Testimonial Knowledge and Transmission,' The Philosophical Quarterly 49 (197):471-490.

Lackey, Jennifer (2007). 'Norms of Assertion,' Noûs 41 (4):594-626.

McKinnon, Rachel (2013). 'The Supportive Reasons Norm of Assertion,' American Philosophical Quarterly 50 (2):121-135.

McKinnon, Rachel (2015). The Norms of Assertion: Truth, Lies, and Warrant, New York: Palgrave Macmillan.

Stalnaker, Robert (1978). 'Assertion,' in P. Cole (ed.), Pragmatics, New York: New York Academic Press, Vol. 9:315-32

Sosa, Ernest (2011). Knowing Full Well, Princeton: Princeton University Press.

Stanley, Jason (2008). 'Knowledge and Certainty,' Philosophical Issues 18:35-57.

Turri, John (2011). 'The Express Knowledge Account of Assertion,' Australasian Journal of Philosophy 89 (1):37-45.

Unger, Peter (1975). Ignorance: A Case for Scepticism, Oxford: Oxford University Press. 
Weiner, Matthew (2005). 'Must we know what we say?' The Philosophical Review $114(2): 227-251$.

Whitcomb, Dennis (2013). 'One Wage of Unknowability,' Synthese 190 (3):339-352.

Willard-Kyle, Christopher (ms). 'P, but You don't Know that P.'

Williamson, Timothy (2000). Knowledge and its Limits, Oxford: Oxford University Press. 